\title{
The Stability's Influencing Factors and Active Control of Hydrostatic Journal Bearing
}

\author{
Peng Liang ${ }^{\mathrm{a}}$, Changhou Lu ${ }^{\mathrm{b}}$, Shujiang Chen, Jie Ding \\ School of Mechanical Engineering, Shandong University, Jinan, Shandong, 250061, China \\ aliangpeng2009@126.com, bluchh@sdu.edu.cn
}

Keywords: hydrostatic journal bearing, active control, restrictor, bearing structure

\begin{abstract}
The hydrostatic bearings are widely applied in the field of high-speed precision grinding machine due to high precision and high stiffness. But in order to make the hydrostatic bearings more fit for the precision machining with high speed, we have to solve the instability problem of system due to rotor vibration. The factors that have effect on the stable characteristic of hydrostatic bearings are analyzed and commented. Then the research status of active control of hydrostatic journal bearing is studied. At last we take the prospect and forecast of hydrostatic bearing's development tendencies.
\end{abstract}

\section{Introduction}

Hydrostatic journal bearing is one kind of sliding bearing. It has advantages of small friction coefficient, long operation life, and high reliability. With the development of grinding machine, the spindles supported by hydrostatic bearing are widely used. But the rotor of system is easy to vibrate with high rotating speed. So we should study the influence factors of rotor stability. Further studies of bearing characteristics from mechanism aspect are required. And it is necessary to take system analysis and further summarize for the existing research results. The effects of critical factors on the characteristics of bearing are analyzed and commented from the aspects of restrictor and oil recess structure. The future development tendency of hydrostatic bearing technology is predicted and prospected.

\section{Research status of restrictor and bearing structure}

To make the hydrostatic bearing have certain carrying capacity and oil film stiffness, the system must has compensation component which can adjust the oil recess pressure with the variance of external load. The commonly used compensation components can be divided into two types: the fixed restrictor (including capillary restrictor, Orifice restrictor, et al) and the variable restrictor (slide valve feedback restrictor, film feedback restrictor, et al).

Sighn [1] holds that the suitable restrictive parameters are very important for the bearing, and he finds that the bearing system has the maximum stiffness by optimizing restrictive parameters. Sato, et al. [2] take the theoretical and experimental research of hydrostatic thrust bearing's dynamic performance. They find that when the restrictive area adjusts appropriately following variance of oil film thickness, the values of bearing's dynamic stiffness and damping coefficients will increase. And the stability of bearing system can be improved.

Kumar [3] points that the decreasing minimum oil film thickness and poor stability can be improved by optimizing the restrictive parameters of capillary restrictor. And there exist the optimal restrictive ration which can result in the best stiffness and stability. Sharma, et al. [4] analyze the performance of sliding bearing with different restrictive styles (capillary, Orifice, quantitative valve, crack). The results indicate that the bearing with quantitative valve compensated has the best direct stiffness and damping coefficient in the case of identical load and elastic coefficients.

Hango, et al. [5] use piezoelectric actuators to control restrictive clearance. The bearing's stiffness can be obviously increased in a certain range of load fluctuation, and the precision of oil film can be limited within submicron. Chen [6] analyses the effect of restrictive parameters on the stability of a six-cavity bearing with Orifice restrictor. The research demonstrates that the appropriate restrictive parameters are helpful to improve the rigid rotor's stability. 
In recent years, lots of scholars have undertaken studies on the bearing's structure parameters. Chen, et al. [7] have made studies on the performances of shallow-recessed bearing and deep-recessed bearing exert in bearing capacity, stability threshold and whirl ratio. The results indicate that, the stable performance of deep-recessed bearing is better than that of shallow-recessed bearing, when deep-recessed bearing's restriction parameters are reasonably designed and its recess has proper land-width ratio. Sharma, et al. [8] have searched the performance of six-pocket and four-pocket capillary compensated hydrostatic/hybrid flexible journal bearing. The theoretical results show that, under the constant load, the minimum oil film thickness of six-pocket bearing is smaller than that of four-pocket bearing, and six-pocket bearing's maximum oil film pressure is bigger than four-pocket bearing's. Increasing recess number or bearing flexibility can enhance flow of bearing, and so, supply pressure of six-pocket bearing is bigger than four-pocket bearing's. In terms of stability, six-pocket recess bearing has higher stability than four-pocket bearing.

Yoshimoto, et al. [9] study the influence of capillary restrictor compensated hybrid bearing's recess size on carrying capacity. They argue that increasing recess size can enhance hydrostatic effect and bearing capacity under the situation of zero-speed. And decreasing recess size can reinforce the hydrodynamic effect and improve the supporting ability of dynamic load under the situation of high-speed. Harnoy, et al. [10] introduce a new bearing which integrates hydrodynamic journal bearing and rolling bearing. Such kind of bearing is the equivalent of rolling bearing at a low speed, and amounts to hydrodynamic bearing at a high speed. If designed reasonably, this kind of bearing is better than traditional bearing in terms of wear and thermal characteristics, and can reduce risk due to bearing's catastrophic failure in safety. Jadon, et al. [11] study the impacts of parameters of bearing structure and oil-supply hole on bearing's performance, and present relevant optimized methods of structure parameter and oil-supply hole's arrangement.

\section{Active control of hydrostatic journal bearing}

In the same way, to improve stability when hydrostatic bearing rotates, we can directly inject lubricating oil with certain pressure into clearances of the bearing through hydraulic control system or the restrictor, which is called active sliding bearing.

Santos, et al. [12] have achieved active lubrication through controlling static pressure by mechanical and electronic system, through which cross stiffness parameter can be decreased and direct damping parameter increased. And finally, stability of bearing-rotor system gets enhanced. Dange [13] provides an equipment which can control oil film thickness of hydrostatic thrust bearing. Such equipment can change the pressure of supply oil by piston and valve, with the advantages of automatically compensating the influence due to oil viscosity's changes, as well as the advantages of consistent oil film thickness under different loads. Santos, et al. [14] have studied journal bearing with multiple-recesses bearing. They have controlled oil flow injected into recess through servo valve control system, which possibly changes active hybrid pressure and then, is beneficial to reduce the vibration of rotor system.

Sun, et al. [15] provide a controller which can take self-regulatory to forced vibration of rotating system. This control algorithm can restrain rotor vibration in the case that we do not know the system parameters and distribution of unbalance oil film pressure. Cai [16] finds that hydrostatic bearing and hybrid bearing with oil film lubrication are suitable to control pressure area actively to reach the stability situation. They have studied the active control problems of titling pads sliding bearing. By controlling the pad's radical movement, the rotor vibration can be limited and the system's stability can be improved. Santos, et al. [17] have made studies on the issue of dynamic damping coefficient of titling-pad journal bearings. They, through regulating the parameters of proportional valve connected with bearing recess, change recess pressure, then altering pad's displacement and bearing's clearance. They have also analyzed advantages and limitations of such control method applied to high-speed processing. Krodriewski, et al. [18] realize the bearing's active control by adjusting flexible oil pad's migration.

Sun, et al. [19, 20] design a new bearing which includes deformable thin wall. Hydraulic valve controls recess pressure to adjust the thin wall's deformation in the operation, then, changing the 
bearing's clearance, namely, oil film thickness, and pressure distribution. Therefore, dynamic response of rotor can be controlled online, and the system's stability can be improved. Chen and Yau $[21,22]$ utilize electrohydraulic system to control static pressure recess's stress of squeeze film dampers, and properly choose control parameter, which can prohibit rotor's chaotic motion, or convert the chaotic motion into periodic motion, enhancing stability of rotor's motion.

\section{Development of hydrostatic bearing}

With machines' development towards high-efficiency and precision, bearing technology faces challenge. To improve the grinding precision, suitable spindle structure, recess number and recess parameter are necessary. Temperature is an affect seriously factor of hydrostatic bearing. So we should take cooling action. To further improve the dynamic stiffness, the present hydrostatic bearing develops toward high supply pressure. And this can meet requirement of rough and fishing machining. There are numerous issues worth discussion, on bearing's recess structure, material, lubricant medium, turbulence, eddy current, etc., which can provide bearings with marvelous dynamic stiffness, stability, as well as low friction resistance under high-speed. The varies of bearing's clearance due to the thermal expansion coefficients of different materials when the bearing is designed. As to hydrostatic spindle operating under high-speed and heavy load, comprehensive consideration should be given to effects of dynamic pressure, heat, squeeze film, and oil compressibility, as well as influences exerted by spindle and bearings elastic deformation.

\section{Conclusions}

The restrictor's types and parameters have an important influence on the stability of bearing system. The bearing's recess numbers, structure, size, etc. also play an important effect on the bearing system's stability. Though many scholars present some active control methods of hydrostatic bearing, there exist some difficulties in active control.

\section{Acknowledgements}

This paper is supported by National Natural Science Foundation of China (No.51075242). It is also supported by the Graduate Independent Innovation Fund of Shandong University (No. yzc12125).

\section{References}

[1] C.K. Sighn, D.V. Singh. Wear. Vol. 44(1977). p. 223.

[2] Y. Sato, K. Maruta, M. Harada. Tribology Transaction. Vol. 110(1988). p. 159.

[3] V. Kumar, S. C Sharma, S. C. Jain. Tribology International. Vol. 39(2006). p. 356.

[4] S. C Sharma, S. C. Jain, N. M. Reddy. Tribology Transactions. Vol. 44(2001). p. 310.

[5] T. Hango, M. Harada, R. Miyaji. Japan Society of Lubrication Engineers. Vol. 32(1987). p. 849

[6] C. H. Chen, Y. Kang, Y. N. Huang, et a1. Industrial Lubrication Tribology. Vol. 54(2002). p. 255.

[7] C. H. Chen, Y. Kang, Y. N. Huang, et a1. Tribology International. Vol. 35(2002). p. 849.

[8] S. C. Sharma, S. C. Jain, R. Sinhasan, et al. Tribology International. Vol. 20(1995). p. 531.

[9] S. Yoshimoto, W. B. Rowe, D. Ives. Wear. Vol. 127(1988). p. 307.

[10] A. Harnoy, M. M. Khonsari. Tribology Transaction. Vol. 39(1996). p. 455.

[11] V. K. Jadon, M. Singh. Industrial Lubrication Tribology. Vol. 59(2007). p. 92.

[12] I. F. Santos. Journal of Tribology. Vol. 126(2004). p. 146.

[13] Y. K. Dange. Indian Journal of Technology. Vol. 14(1976). p. 552.

[14] I. F. Santos, F. Y. Watanabe. Journal of the Brazilian Society of Mechanical Sciences and Engineering. Vol. 25(2003). p. 154.

[15] L. Sun, J. M. Krodkiewski, Y. Cen. Journal of Sound and Vibration. Vol. 213(1998). p. 1.

[16] Z. Cai, M. S. Queiroz, M. M. Khonsari. Journal of Sound and Vibration. Vol. 273(2004). p. 421. 
[17] I. F. Santos. Tribology Transactions. Vol. 38(1995). p. 700.

[18] J. M. Krodriewski, G. J. Davies. Proceedings of the ASME Turbo Expo. Vol. 6(2004). p. 799.

[19] L. Sun, J. M. Krodriewski, N. Zhang. American Society of Mechanical Engineers. Vol. (1994). p. 1.

[20] L. Sun, J. M. Krodriewski. Journal of Sound and Vibration. Vol. 230(2000). p. 1103

[21] C. L. Chen, H. T. Yau, Y. H. Li. Journal of Vibration and Acoustics, Transactions of the ASME. Vol. 124(2002). p. 198.

[22] H. T. Yau, C. L. Chen. Journal of Vibration and Acoustics, Transactions of the ASME. Vol. 128(2006). p. 176. 